\title{
CRIOTOLERÂNCIA DE OÓCITOS E EMBRIÕES BOVINOS MATURADOS COM LÍQUIDO FOLICULAR E/OU $\beta$-MERCAPTOETANOL
}

\section{CRYOTOLERANCE OF BOVINE OOCYTES AND EMBRYOS MATURATED WITH FOLLICULAR FLUID AND/OR $\beta$-MERCAPTOETHANOL}

\author{
Monalyza Cadori Gonçalves ${ }^{1}$ \\ Matheus Pedrotti Cesaro ${ }^{2}$ \\ Murilo Farias Rodrigues ${ }^{3}$ \\ Rui Félix Lopes ${ }^{4}$ \\ Joana Claudia Mezzalira 5 \\ Fabricio Desconsi Mozzaquatro 6 \\ Alceu Mezzalira ${ }^{6}$ \\ 1 Pós-graduanda da Universidade Federal do Rio Grande do Sul, Porto Alegre, RS, Brasil. \\ 2 Pós-Graduando da Universidade Federal de Santa Maria, Santa Maria, RS, Brasil \\ ${ }^{3}$ Médico Veterinário, Mestre, Equiservice Veterinária., Balneário Arroio do Silva, SC, Brasil \\ ${ }^{4}$ Professor Doutor da Universidade Federal do Rio Grande do Sul, Porto Alegre, RS, Brasil. \\ ${ }^{5}$ Médica Veterinária, Mestre, Universidade do Estado de Santa Catarina, Lages, SC, Brasil \\ ${ }^{6}$ Professores Doutores da Universidade do Estado de Santa Catarina, Lages, SC, Brasil - \\ fmozzaquatro@yahoo.com.br
}

\section{Resumo}

Foi avaliada a criotolerância de oócitos e embriões bovinos maturados com adição de líquido folicular (LF) e/ou $\beta$-mercaptoetanol (BM). Após vitrificação, os oócitos foram maturados em: TCM-199

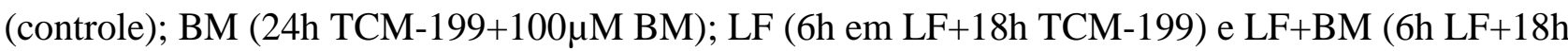
TCM-199+100 $\mu \mathrm{M}$ BM). Não houve diferença $(\mathrm{p}>0,05)$ nas taxas de blastocistos dos tratamentos TCM (6,4\%), BM (4,0\%) e LF (3,4\%). A eclosão e densidade celular dos embriões eclodidos não diferiram ( $p>0,05)$ nos tratamentos. No Experimento 2 blastocistos expandidos (Bx) obtidos em D7 ou D8 foram vitrificados, avaliando-se sua reexpansão e eclosão. A reexpansão foi semelhante ( $>$ >0,05), sendo observado comportamento distinto na eclosão entre Bx D7 e D8. Nos Bx D7 houve maior eclosão no controle (TCM-54,2\%) em relação ao BM (40,32\%) e LF+BM (33,89\%). Os Bx D8 apresentaram menor eclosão no controle (TCM) em relação aos Bx D7. Nos tratamentos BM, LF e LF+BM a eclosão foi semelhante para Bx D7 ou D8. A maturação com adição de LF e/ou BM não melhora a criotolerância de oócitos imaturos e embriões PIV. Blastocistos expandidos precoces (D7) são mais criotolerantes e apresentam um comportamento distinto à adição de LF e BM, em relação aos tardios (D8).

Palavras-chave: aditivos; criotolerância; embrião PIV; maturação; vitrificação.

\section{Abstract}

Cryotolerance of bovine oocytes and embryos maturated with addition of follicular fluid (LF) and $\beta$ - 
mercaptoethanol (BM) was evaluated. After vitrification, oocytes were maturated in: TCM-199 (control); BM (24h TCM-199+100 $\mu$ M BM); LF (6h in LF+18h TCM-199), and LF+BM (6h LF+18h TCM-199+100 $\mu \mathrm{M} \mathrm{BM})$. There was not difference ( $p>0.05)$ in blastocysts rate in TCM (6.4\%), BM (4.0\%) and LF (3.4\%) treatments. The hatching rates and cell density of hatched embryos did not differ ( $p>0.05$ ) among treatments. In Experiment 2, hatched blastocysts (Bx) obtained in D7 or D8 were vitrified and evaluated according to its expanding and hatching rates. The expanding rate was similar ( $p>0.05$ ), being observed a distinct pathway in hatching rate in D7 and D8 Bx. Higher hatching rate was observed in D7 Bx from control (TCM-54.2\%) compared to BM (40.32\%) and LF+BM (33.89\%) treatments. The D8 Bx showed lower hatching rate in control (TCM-199) compared with D7 Bx. In BM, LF and LF+BM treatments, the hatching rate was similar for D7 or D8 embryos. Maturation with addition of LF and/or BM does not increase the oocyte or IVP embryo cryotolerance. Expanded blastocysts (D7) have higher cryotolerance and show a distinct pathway when added with LF or BM, in comparison with D8 embryos.

Keywords: additives; cryotolerance; IVP embryos; maturation; vitrification.

Recebido em: 25 novembro 2013

Aceito em: 04 fevereiro 2015

\section{Introdução}

A criopreservação de oócitos e embriões de mamíferos é uma etapa importante na reprodução assistida humana e animal. Nos últimos anos, avanços importantes foram obtidos na metodologia de criopreservação de oócitos e embriões bovinos produzidos in vitro (PIV), como o nascimento de produtos derivados de oócitos vitrificados ${ }^{(1)}$ e maior taxa de embriões provenientes de oócitos bovinos vitrificados com elevadas taxas de resfriamento e reaquecimento ${ }^{(2-4)}$. No entanto, os resultados da criopreservação ainda são pobres, possivelmente pelas diferenças decorrentes da produção in vitro em relação à produção in vivo.

A qualidade dos oócitos é um fator determinante para o desenvolvimento embrionário. Além disso, as condições de cultivo podem influenciar a produção, a qualidade e a criotolerância dos embriões produzidos in vitro ${ }^{(5,6)}$. A falta de sincronia entre a maturação citoplasmática e nuclear dos oócitos é apontada como uma causa importante da baixa viabilidade dos embriões resultantes ${ }^{(7)}$ que, consequentemente, são menos criotolerantes. Durante a seleção dos oócitos, após a aspiração folicular, é difícil identificar oócitos com maior ou menor competência, pois, in vitro, a maturação nuclear ocorre de uma forma assíncrona em relação à maturação citoplasmática ${ }^{(8)}$.

In vivo, o líquido folicular (LF) é sintetizado pelas células que compõem a parede do folículo, sendo composto por inúmeras sustâncias que atuam como fonte nutricional, dando suporte ao desenvolvimento do oócito ${ }^{(9)}$. O LF apresenta um importante papel no processo de maturação oocitária, bloqueando de forma variável a maturação nuclear antes da ovulação. A adição de líquido folicular nos meios de maturação in vitro tem sido proposta por vários autores ${ }^{(9,10)}$, procurando adequar o ambiente in vitro e proporcionar adequada competência oocitária e criotolerância.

Outro fator que interfere na qualidade dos oócitos e embriões é o estresse oxidativo ${ }^{(11-13)}$. Oócitos e embriões produzidos in vitro acumulam radicais livres em excesso, especialmente as espécies reativas de oxigênio (EROs), originadas dos processos oxidativos fisiológicos. Esses radicais livres produzem 
alterações estruturais e funcionais nas células danificando as mitocôndrias, diminuindo a quantidade de adenosina trifosfato (ATP), alterando a quantidade de íons cálcio durante a fertilização e induzindo a apoptose celular ${ }^{(14,15)}$. Em condições fisiológicas, os oócitos e embriões são protegidos dos EROs por sequestradores de oxigênios do líquido folicular e fluído do oviduto. Porém, no cultivo in vitro, há um aumento na concentração das EROs em relação à de antioxidantes. Isso ocorre devido à excessiva concentração atmosférica de oxigênio, à excessiva manipulação, aos processos de crescimento, diferenciação e divisão celular e à carência de sistemas antioxidantes naturais ${ }^{(12,16,17)}$. Para que os processos metabólicos dependentes de EROs ocorram adequadamente e a fisiologia celular seja mantida, é necessário um equilíbrio entre a formação e a remoção das mesmas. Os meios utilizados na PIV não possuem um sistema antioxidante ajustado à necessidade dessas estruturas, possibilitando que oócitos e embriões PIV sofram estresse oxidativo com a consequente redução de sua qualidade e sobrevivência ${ }^{(18)}$.

Nos gametas o sistema antioxidante mais abundante é realizado pela enzima glutationa (GSH). Há um aumento na concentração de GSH intracelular quando os oócitos progridem do estágio de vesícula germinativa para o de metáfase II $^{(19)}$. A GSH também participa da descondensação do material genético do espermatozóide, em paralelo à ativação do oócito, e na transformação do espermatozóide em pró-núcleo masculino ${ }^{(20)}$. Assim, o aumento da síntese de GSH nos oócitos em maturação pode melhorar sua qualidade e o desenvolvimento embrionário. Contudo, a síntese de GSH é dependente da disponibilidade de cisteína no meio extracelular ${ }^{(20,21)}$ que, em sua maior parte, é encontrada na forma oxidada, a cistina ${ }^{(22)}$. Como os oócitos não possuem transportadores para cistina, a síntese de GSH é limitada à assimilação deste peptídeo pelas células do cumulus ${ }^{(16)}$. Como forma de contornar esta situação, componentes do tiol, como o $\beta$-mercaptoetanol (BM) têm sido utilizados para manter a cisteína em sua forma reduzida, através de uma troca sulfidril-disulfito, permitindo o aumento na síntese de $\mathrm{GSH}^{(20,22,23)}$.

Assim sendo, ações que possibilitem o equilíbrio entre a formação e a remoção das EROs, bem como uma melhor sincronia entre os processos de maturação nuclear e citoplasmática nos oócitos, podem resultar em estruturas de melhor qualidade e criotolerantes.

Este estudo avaliou se a adição de LF e/ou B-mercaptoetanol no meio de maturação in vitro influenciaria no desenvolvimento/qualidade do oócito (criopreservado ou não), o que pode refletir em produção de embriões de melhor qualidade.

\section{Material e Métodos}

Exceto quando indicado, todos os produtos utilizados nos experimentos foram provenientes do laboratório Sigma-Aldrich Química Ltda. (Sigma Chemical CO, St. Louis, MO, USA).

Ovários bovinos obtidos em abatedouros foram mantidos a $25-35^{\circ} \mathrm{C}$, em solução salina tamponada com fosfato (PBS) adicionada de penicilina $(100 \mathrm{UI} / \mathrm{mL})$ e estreptomicina $(0,05 \mathrm{mg} / \mathrm{mL})$, durante o transporte ao laboratório. O tempo entre coleta dos ovários e processamento teve duração de 2 a 8 horas. Os complexos cumuli oócitos (CCOs) foram aspirados de folículos de 2 a $8 \mathrm{~mm}$ de diâmetro para o interior de um tubo cônico $(15 \mathrm{~mL})$, através de um scalp $19 \mathrm{G}$ ligado a uma linha de vácuo com pressão de aspiração correspondente à obtenção de um fluxo de $20 \mathrm{~mL} / \mathrm{minuto}$. Após dez minutos de espera, o sedimento dos tubos foi passado para uma placa de Petri $(90 \times 15 \mathrm{~mm})$ para a busca dos CCOs. Depois de recuperados, os CCOs foram selecionados no próprio líquido folicular 
centrifugado. A busca e seleção foram realizadas sob lupa estéreo-microscópica, sendo utilizados apenas oócitos com citoplasma homogêneo e totalmente envoltos por células do cumulus oophorus compactas. No Experimento 1, os CCOs selecionados foram vitrificados e, após o reaquecimento, foram distribuídos aleatoriamente entre os quatro tratamentos de maturação. No Experimento 2, a distribuição entre os tratamentos foi realizada logo após a seleção do CCOs.

Foram conduzidos dois experimentos sendo: Experimento 1: vitrificação de oócitos imaturos; Experimento 2: vitrificação de blastocistos expandidos dos dias 7 (D7) e 8 (D8) de cultivo, apenas os de qualidade excelente ou boa.

Nos dois experimentos, os oócitos foram aleatoriamente alocados em um dos quatro tratamentos de maturação descritos a seguir: Tratamento TCM: 24 h de maturação em TCM-199 (controle); Tratamento BM: 24 h de maturação em TCM-199 + $100 \mu$ M BM; Tratamento LF: 6 h em LF seguidas de 18 h de maturação em TCM-199; Tratamento LF+BM: 6 h em LF seguidas de 18 h de maturação em TCM-199 + BM. Cada experimento constou de dez repetições.

Logo após a seleção (Experimento 2) ou vitrificação e reaquecimento (Experimento 1), os CCOs foram divididos aleatoriamente em grupos de 25 (Experimento 1) ou 30 (Experimento 2) e submetidos aos diferentes tratamentos.

Os CCOs dos Experimentos 1 e 2 foram transferidos para a estufa de cultivo em placas Nunc de quatro poços (Nunclon ${ }^{\mathrm{TM}}$, Nunc S/A, Roskilde, Denmark; Cat.176740) contendo $400 \mu \mathrm{L}$ de meio de maturação TCM-199 - sais de Earle adicionado de 26,2 mM de $\mathrm{NaHCO}_{3}, 25 \mathrm{mM}$ de HEPES, 0,2 $\mathrm{mM}$ de piruvato de sódio com 0,01 UI de FSH/mL (Folltropin - Bioniche, Canada), 0,5 $\mu \mathrm{g} / \mathrm{mL}$ de LH (Lutropin - Bioniche, Canada) e 10\% de soro de égua em estro (SEE), suplementado ou não de BM. Os CCOs correspondentes aos tratamentos LF e LF+BM foram colocados em tubos cônicos de 1,5 $\mathrm{mL}$ contendo $1 \mathrm{~mL}$ de $\mathrm{LF}$ centrifugado ${ }^{(24)}$, mantidos à temperatura de $30^{\circ} \mathrm{C}$ em banho maria, por 6 horas, quando, então, foram transferidos para estufa de cultivo em placas Nunc de quatro poços, nas mesmas condições dos tratamentos TCM e BM.

A maturação em estufa de cultivo (Haeraeus Instruments $\mathrm{GmbH}$, Alemanha) foi realizada por $24 \mathrm{~h}$ (TCM e BM) ou $18 \mathrm{~h}(\mathrm{LF}$ e $\mathrm{LF}+\mathrm{BM})$ à temperatura de $39^{\circ} \mathrm{C}$, em atmosfera de $5 \%$ de $\mathrm{CO}_{2}$ e umidade saturada.

Os espermatozóides, de um único touro bos-taurus, foram selecionados pela técnica de migração ascendente (swim-up) em meio TALP-Sperm suplementado com $6 \mathrm{mg} / \mathrm{mL}$ de albumina sérica bovina (BSA), mantidos a $39{ }^{\circ} \mathrm{C}$, em banho-maria. Após 1 hora de migração ascendente, o sobrenadante foi centrifugado por 5 minutos e o pellet aspirado e diluído para obtenção de uma dose inseminante de 1 a 1,5 x $10^{6}$ espermatozóides $/ \mathrm{mL}$.

Após a maturação, os CCOs foram depositados em $400 \mu \mathrm{L}$ de meio TALP-Fert, em placas Nunc de quatro poços, com adição de $30 \mu \mathrm{g} / \mathrm{mL}$ de heparina, $30 \mu \mathrm{g} / \mathrm{mL}$ de penicilinamina, $15 \mu \mathrm{M}$ de hipotaurina e $1 \mu \mathrm{M}$ de epinefrina. Os CCOs foram co-cultivados com os espermatozóides por 18-22 horas (D0), em estufa de cultivo a $39{ }^{\circ} \mathrm{C}$ em atmosfera de $5 \%$ de $\mathrm{CO}_{2}$ e umidade saturada. Após a fecundação (D1), os prováveis zigotos foram submetidos à agitação mecânica em meio TCM-HEPES, por 1 minuto, para remoção das células do cumulus.

Imediatamente após o desnudamento, os prováveis zigotos foram cultivados em $400 \mu \mathrm{L}$ de meio SOFaaci suplementado com $6 \mathrm{mg} / \mathrm{mL}$ de BSA, sob óleo mineral, em placas de quatro poços. As placas foram mantidas em bolsa impermeável a gases $\left(\right.$ Bag-system $\left.^{25}\right)$, com uma mistura gasosa contendo $90 \%$ de $\mathrm{N}_{2}, 5 \%$ de $\mathrm{O}_{2}$ e $5 \%$ de $\mathrm{CO}_{2}$ desde o início do cultivo (Experimento 1) ou após a avaliação da clivagem (D2; Experimento 2) em estufa a $39{ }^{\circ} \mathrm{C}, 5 \% \mathrm{CO}_{2}$ e máxima umidade relativa. 
Os CCOs foram vitrificados em micropipetas de vidro estiradas com diâmetro interno de aproximadamente $0,35 \mathrm{~mm}$, em grupos de 3 a 5 estruturas. As soluções de vitrificação e reaquecimento foram preparadas a partir de TCM-199, tamponado com HEPES e adicionado de 10\% de SEE.

Logo após a punção e seleção, os CCOs a serem vitrificados foram expostos por 30 segundos a uma solução de equilíbrio com 10\% Etilenoglicol (EG) + 10\% Dimetil sulfóxido (DMSO), seguido de 20 segundos de exposição na solução de vitrificação com 20\% EG +20\% DMSO + 0,5 M sacarose. Após o envase, as micropipetas foram submersas em nitrogênio líquido, sendo mantidas por aproximadamente 30 minutos até o reaquecimento. O reaquecimento foi realizado através da exposição ao ar por dois a três segundos e imersão em soluções decrescentes de sacarose $0,30 \mathrm{M} \mathrm{e}$ $0,15 \mathrm{M}$, à temperatura de $35^{\circ} \mathrm{C}$. Após cinco minutos em cada solução, foram depositados em TCMHEPES com $10 \%$ de SEE.

Após o reaquecimento, $25 \mathrm{CCOs}$ foram transferidos para cada um dos quatro tratamentos descritos. Os tubos de 1,5 mL com LF contendo os tratamentos LF e LF+BM foram mantidos por seis horas à $30^{\circ} \mathrm{C}$, quando os CCOs passaram para o meio de maturação (TCM-199) com incubação em estufa de cultivo por $18 \mathrm{~h}$. Um grupo controle não vitrificado foi mantido em LF até o final da vitrificação e submetido aos mesmos procedimentos de produção in vitro dos tratamentos vitrificados. Com sete, oito e nove dias de cultivo, foram avaliadas as taxas de clivagem, blastocistos e eclosão, respectivamente. Os blastocistos eclodidos, em cada tratamento, separados por grau de qualidade morfológica e dia de eclosão, foram fixados em álcool etílico $99 \%$ para avaliação da qualidade através da contagem celular pela coloração de bisbenzimida.

Após alcançarem o estádio de blastocisto expandido (D7 e D8), os embriões de qualidade boa ou excelente de cada tratamento foram vitrificados. Durante todo o processo, os embriões foram mantidos separados de acordo com seu tratamento inicial.

A vitrificação foi realizada através da exposição por 1 minuto à solução de equilíbrio composta de $10 \%$ EG $+10 \%$ Propilenoglicol (PROP), seguida de 25 segundos de exposição à solução de vitrificação composta de $20 \% \mathrm{EG}+20 \%$ PROP. Em cada micropipeta de vidro foram envasados, em média, 3 embriões.

$\mathrm{O}$ reaquecimento foi realizado pela exposição ao ar por dois a três segundos e imersão em soluções decrescentes de sacarose $0,30 \mathrm{M}$ e $0,15 \mathrm{M}$ (cinco minutos cada), em temperatura de $35^{\circ} \mathrm{C}$. Após o reaquecimento, os embriões foram colocados em cultivo complementar para avaliação de sua capacidade de reexpansão e eclosão in vitro, sendo considerados viáveis os que atingiram o estádio de blastocisto eclodido (Be).

Os embriões eclodidos de cada tratamento foram subjetivamente classificados, de acordo com sua morfologia em G1 (excelente), G2 (bom) ou G3 (ruim), e fixados em álcool etílico 99\% para determinação da contagem de células pela coloração de bisbenzimida, conforme pré estabelecido em trabalho de WERLICH et al. ${ }^{(3)}$.

No Experimento 1, a taxa de clivagem foi realizada no D7, junto à avaliação da taxa de blastocistos. No Experimento 2, a taxa de clivagem foi determinada após 24 horas de cultivo (D2).

Ao final do período de cultivo (D7), foi determinada a taxa de desenvolvimento embrionário nos 4 tratamentos de cada um dos experimentos. Uma segunda avaliação foi realizada no oitavo dia de cultivo. Para o cálculo da taxa de blastocisto, considerou-se desde o estádio de blastocisto inicial (Bi) no Experimento 1, e blastocisto (B1) no Experimento 2, sempre em relação ao número de estruturas inicialmente cultivadas. 
No Experimento 2, a taxa de reexpansão e eclosão foi avaliada após o reaquecimento dos embriões durante um período de até 5 dias.

Os blastocistos eclodidos de cada tratamento foram separados por dia de eclosão e classificação morfológica e corados para quantificar o número de células. Para a contagem celular, após fixação em álcool etílico $99 \%$ por no mínimo 12 horas, os embriões permaneceram por 10 minutos em 10mg/mL de bisbenzimida (Hoechst 33342), em HEPES + 10\% SEE, abrigados da luz. Em seguida, em uma gota de glicerol $(10 \mu \mathrm{L})$ montada entre lâmina e lamínula, foram visualizados sob luz UV em microscópio invertido de epifluorescência para a identificação e contagem dos núcleos celulares. As taxas de clivagem e blastocistos foram submetidas à comparação pelo teste $\chi^{2}$ (pacote estatístico Minitab®, State College, EUA) ou Fisher (planilha Excel, Microsoft@), com nível de significância de $5 \%$. Os valores da contagem celular foram submetidos à análise de variância e comparação de médias pelo teste Tuckey (pacote estatístico Minitab®, State College, EUA).

\section{Resultados e discussão}

Os protocolos de vitrificação tiveram significativos avanços nos últimos anos; entretanto, os baixos resultados de sobrevivência embrionária ainda não viabilizaram a aplicação comercial desta técnica. Neste estudo, foram empregados um antioxidante (BM) e também o LF como aditivos para melhorar as condições de maturação embrionária. A adição de BM no meio de maturação de oócitos vitrificados/reaquecidos melhorou a taxa de clivagem quando comparado ao meio contendo somente LF (54\% [108/200] vs 35\% [71/203], respectivamente). O tratamento BM, ainda apresentou taxas superiores às obtidas pela associação LF+BM (41,1\% [81/197]). Os resultados demonstraram um efeito negativo do líquido folicular na maturação dos oócitos imaturos que foram vitrificados/reaquecidos. Quando comparado ao controle vitrificado (Grupo TCM), a inclusão do BM não influenciou as taxas de clivagem (Tabela 1).

Tabela 1: Taxas de clivagem, blastocisto e eclosão de embriões obtidos de oócitos vitrificados e maturados por $24 \mathrm{~h}$ em TCM-199 (TCM); $24 \mathrm{~h} \mathrm{em} \mathrm{TCM-199} \mathrm{+} 100 \mu \mathrm{M}$ BM (BM); expostos por 6 $\mathrm{h}$ em líquido folicular $+18 \mathrm{~h}$ em TCM-199 (LF), ou expostos por $6 \mathrm{~h}$ em líquido folicular $+18 \mathrm{~h}$ em TCM-199 + $100 \mu \mathrm{M}$ BM (LF+BM), bem como de oócitos controle não-vitrificados e maturados em TCM-199 (CONTROLE)

\begin{tabular}{|c|c|c|c|c|c|}
\hline \multirow{3}{*}{ Tratamento } & \multirow{3}{*}{ Cultivados } & \multirow{2}{*}{$\begin{array}{l}\text { Taxa de } \\
\text { clivagem }\end{array}$} & \multicolumn{2}{|c|}{ Taxa de blastocisto } & \multirow{2}{*}{$\begin{array}{l}\text { Taxa de } \\
\text { Eclosão }\end{array}$} \\
\hline & & & D7 & D7+D8+D9 & \\
\hline & & $\%(\mathrm{n})$ & $\%(\mathrm{n})$ & $\%(\mathrm{n})$ & $\%(n)$ \\
\hline TCM & & & & & \\
\hline (Controle vitrificado) & 202 & $50,5(102)^{b c}$ & $3,5(7)^{b}$ & $6,4(13)^{b}$ & $46,1(6)^{a}$ \\
\hline $\mathrm{BM}$ & 200 & $54,0(108)^{b}$ & $2,5(5)^{b}$ & $4,0(8)^{b}$ & $37,5(3)^{\mathrm{a}}$ \\
\hline LF & 203 & $35,0(71)^{\mathrm{d}}$ & $2,0(4)^{b}$ & $3,4(7)^{\mathbf{b}}$ & $28,6(2)^{\mathbf{a}}$ \\
\hline $\mathrm{LF}+\mathrm{BM}$ & 197 & $41,1(81)^{\text {cd }}$ & $0^{\mathbf{c}}$ & $0^{\mathbf{c}}$ & - \\
\hline CONTROLE & 223 & $83,0(185)^{\mathbf{a}}$ & $34,1(76)^{\mathbf{a}}$ & $35,4(79)^{\mathbf{a}}$ & $43(34)^{a}$ \\
\hline
\end{tabular}

$\mathrm{a}, \mathrm{b}, \mathrm{c}, \mathrm{d}$ Letras diferentes na mesma coluna indicam diferença significativa $(\mathrm{P}<0,05)$. 
O desenvolvimento embrionário dos oócitos criopreservados foi similar no grupo BM e LF, não diferindo do grupo controle vitrificado (TCM). Porém, na comparação entre os grupos vitrificados e não vitrificados, observa-se que a taxa de desenvolvimento e produção de embriões foi muito inferior nos grupos vitrificados, demonstrando os efeitos deletérios da criopreservação na estrutura dos gametas (Tabela 1).

A associação LF+BM apresentou efeitos negativos consideráveis, impedindo que qualquer estrutura atingisse o estágio de blastocisto. A inclusão do LF nos meios de cultivo in vitro é antiga e controversa. Alguns autores demonstraram que o tamanho do folículo e o estádio do ciclo estral influenciam a capacidade inibidora do LF na maturação nuclear. Ayoub e Hunter ${ }^{(26)}$ observaram maior inibição com LF de folículos pequenos e médios $(2-9 \mathrm{~mm})$, obtidos durante o estro, com redução do efeito inibidor fora deste período. Já folículos maiores, podem estimular ao invés de inibir a maturação nuclear ${ }^{(27)}$. Nos dois experimentos deste estudo, o LF foi obtido de um pool dos folículos puncionados de ovários obtidos em abatedouro e, portanto, sem controle da fase estral das fêmeas doadoras, o que pode ter contribuído para o efeito adverso observado. Adicionalmente, é ainda possível que tenha ocorrido a exposição dos oócitos a fatores deletérios provenientes de folículos atrésicos, ou mesmo de maior diâmetro, já que durante a punção não era possível aferir de forma precisa o tamanho folicular. Outra característica relevante é a relação inversa entre a faixa etária e a concentração das enzimas envolvidas na desintoxicação de EROs, como a glutationa transferase, observada em humanos ${ }^{(28)}$ e bovinos $^{(29)}$. Como geralmente não se conhece a idade das vacas utilizadas nos distintos experimentos, é possível que este seja um importante fator responsável pelos resultados controversos em diferentes estudos sobre a composição e o efeito da utilização do LF durante a MIV. Essas características não foram consideradas neste estudo, já que se buscou uma forma prática de obter o LF que possibilitasse o emprego imediato na produção in vitro de embriões. Isso determinou que os próprios folículos puncionados na obtenção dos oócitos fossem a fonte do LF.

A baixa qualidade de oócitos e embriões PIV é um importante fator que interfere na criotolerância. O estresse oxidativo, que se caracteriza pelo desequilíbrio entre a formação de radicais livres e a sua remoção, tem sido implicado na baixa qualidade embrionária. No Experimento 2 avaliou-se a influencia do BM, LF, bem como a sua associação $\mathrm{LF}+\mathrm{BM}$ no meio de maturação in vitro e posterior desenvolvimento embrionário (Figura 1). As taxas de clivagem foram semelhantes entre o tratamento BM (73,9\% [380/514]) e o grupo TCM (controle - 77,5\% [397/512]). Não houve diferença entre a taxa de clivagem dos tratamentos BM e LF (71,0\% [352/496]). Porém o acréscimo de LF diminuiu as taxas de clivagem quando os resultados são comparados ao grupo TCM (controle). Ainda, o tratamento LF+BM apresentou 60,3\% (313/519) de clivagem, significativamente inferior aos demais tratamentos $(\mathrm{P}<0,05$, ver Figura 1$)$.

$\mathrm{Na}$ avaliação em D7, a maior taxa de blastocisto foi observada no tratamento TCM (28,3\% - 145/512), sendo semelhante à do tratamento $\operatorname{LF}(24,2 \%$ - 120/496). A taxa de blastocistos dos tratamentos LF e BM $(22,4 \%$ - 115/514) não apresentaram diferenças estatísticas. Já a menor taxa de blastocistos foi observada no tratamento LF+BM (18,1\% - 94/519).

Os experimentos conduzidos não apontaram melhora nas taxas de clivagem, blastocisto ou eclosão dos grupos tratados com BM em relação ao grupo controle. No Experimento 2, no qual os oócitos foram simplesmente cultivados após a exposição em BM na maturação, houve inclusive uma redução na taxa de blastocistos. O uso de BM durante o cultivo in vitro não afetou a taxa de clivagem em relação ao controle $(80,2 \%$ vs. $81,1 \%)$, porém afetou negativamente o desenvolvimento até o estádio de blastocisto $(28,0 \%$ vs. $43,8 \%)$. BAI et al. ${ }^{(30)}$ também não observaram melhora no desenvolvimento 
de oócitos de fêmeas ovinas pré-púberes, suplementados com BM e cisteína durante a maturação.
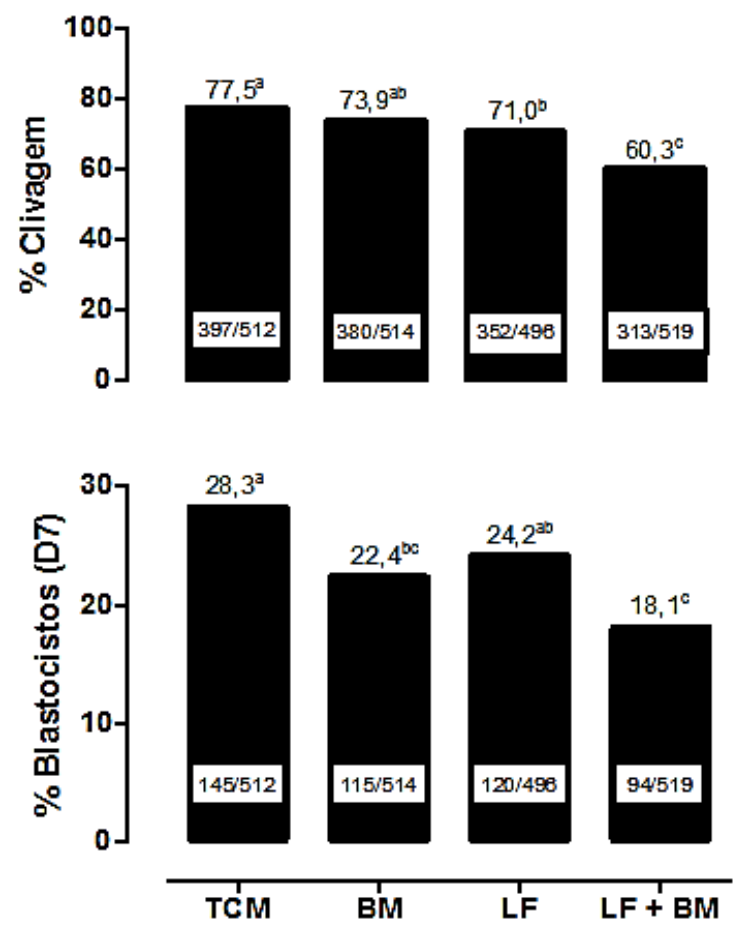

Figura 1: Taxas de clivagem e blastocisto obtidas de oócitos maturados por $24 \mathrm{~h}$ em TCM-199 (TCM); $24 \mathrm{~h}$ em TCM-199 $+100 \mu \mathrm{M} \mathrm{BM}(\mathrm{BM})$; expostos por $6 \mathrm{~h}$ em líquido folicular $+18 \mathrm{~h} \mathrm{em}$ TCM-199 (LF), ou expostos por $6 \mathrm{~h}$ em líquido folicular $+18 \mathrm{~h}$ em TCM-199 $+100 \mu \mathrm{M} \mathrm{BM}$ $(\mathrm{LF}+\mathrm{BM})(\mathrm{P}<0,05)$.

Todavia, estes resultados são distintos dos observados por outros autores, que suplementaram com compostos de tiol na maturação de oócitos e verificaram melhora nas taxas de desenvolvimento embrionário $^{(19,23,31)}$. Entretanto, as taxas de clivagem $(73,9 \%)$ e blastocistos $(22,4 \%)$ obtidas no grupo tratado com BM neste estudo são semelhantes aos 71,1\% e 23,8\% obtidas por De Matos e Furnus $^{(19)}$ nos grupos tratados com BM. Já as taxas de clivagem e blastocistos do grupo controle $(61,8 \%$ e $15,7 \%$, respectivamente) observada pelos autores citados foram inferiores ao controle deste trabalho (77,5\% e 28,3\%, respectivamente). Esses dados podem sugerir que o efeito positivo do BM no meio de maturação ocorre quando as condições de produção são menos adequadas e, assim, proporcionem maior ocorrência de estresse oxidativo. Cabe ainda considerar que, embora nocivos às estruturas celulares, os EROs atuam como mensageiros intracelulares durante o crescimento e diferenciação celular, bem como durante o processo de fecundação ${ }^{(32)}$. É possível que o efeito benéfico do BM na defesa de oócitos e embriões contra os EROs tenha sido mascarado por alterações nas sinalizações fisiológicas das quais esses radicais participam. Entretanto, novos estudos são necessários para comprovar esta hipótese. A literatura descreve que a adição de cisteamina ao meio, mesmo não mostrando efeito positivo na maturação, pode melhorar a competência e a criotolerância embrionária ${ }^{(33)}$; contudo, nas condições deste estudo, o emprego de BM, além de não melhorar a 
viabilidade de oócitos imaturos após a vitrificação (Tabela 1), ainda reduziu a taxa de eclosão dos embriões vitrificados em relação ao grupo sem BM (Tabela 2). Com relação à criotolerância, aparentemente, o BM é mais benéfico se adicionado no cultivo, logo após o processo de criopreservação. Nedambale et al. ${ }^{(34)}$ demonstraram aumento na sobrevivência, eclosão e no número de células de blastocistos bovinos, com a adição de BM no meio de cultivo após a vitrificação, o que também foi observado por GUPTA et al. ${ }^{(35)}$. É possível que o estresse produzido pelo processo de vitrificação, sobre os blastocistos, seja prevenido pela subsequente adição de BM.

Tabela 2: Reexpansão e eclosão de blastocistos expandidos obtidos no dia 7 (D7) ou no dia 8 (D8) de cultivo e vitrificados/reaquecidos. Os embriões foram produzidos em TCM (24h em TCM-199); BM (24h em TCM-199 +100 $\mu \mathrm{M} \mathrm{BM}$ ); LF (6h em líquido folicular + 18h em TCM-199), e LF+BM ( $6 \mathrm{~h}$ em líquido folicular $+18 \mathrm{~h}$ em TCM-199 $+100 \mu \mathrm{M}$ BM)

\begin{tabular}{|c|c|c|c|c|}
\hline \multirow[t]{2}{*}{ Tratamento } & \multicolumn{2}{|c|}{ Reexpansão \% } & \multicolumn{2}{|c|}{ Eclosão \% } \\
\hline & D7 & D8 & D7 & D8 \\
\hline TCM & $72,22(52 / 72)^{a}$ & $55,55(15 / 27)^{\mathrm{a}}$ & $54,2(39 / 72)^{\mathrm{a} / \mathrm{A}}$ & $37,0(10 / 27)^{a / B}$ \\
\hline $\mathrm{BM}$ & $69,23(45 / 65)^{a}$ & $74,19(23 / 31)^{a}$ & $35,38(23 / 65)^{b / A}$ & $29,03(9 / 31)^{a / A}$ \\
\hline $\mathrm{LF}$ & $67,74(42 / 62)^{a}$ & $62,06(18 / 29)^{\mathrm{a}}$ & $40,32(25 / 62)^{a b / A}$ & $31,03(9 / 29)^{a / A}$ \\
\hline $\mathrm{LF}+\mathrm{BM}$ & $57,62(34 / 59)^{\mathrm{a}}$ & $70,96(22 / 31)^{a}$ & $33,89(20 / 59)^{b / A}$ & $22,58(7 / 31)^{a / A}$ \\
\hline
\end{tabular}

${ }^{a, b}$ Letras diferentes na mesma coluna indicam diferença significativa.

${ }^{A}, \mathrm{~B}$ Letras diferentes na mesma linha indicam diferença significativa $(\mathrm{P}<0,05)$.

O tratamento composto pela associação de $\mathrm{LF}$ e BM, produziu resultados inesperados e extremamente nocivos aos oócitos. No Experimento 1, impediu o desenvolvimento de blastocistos, após a vitrificação dos oócitos (Tabela 1). De forma semelhante, houve significativa redução da viabilidade dos oócitos submetidos ao mesmo tratamento no Experimento 2, determinando redução das taxas de clivagem e blastocistos (Figura 1). Entretanto, os embriões produzidos nos diferentes tratamentos apresentaram idêntica sobrevivência após a criopreservação, demonstrada por semelhantes taxas de reexpansão (Tabela 2). Todavia, foi observado um comportamento distinto entre os blastocistos obtidos em D7 ou D8 de cultivo. Nos blastocistos obtidos em D7, observou-se maior taxa de eclosão após a criopreservação no tratamento controle (TCM - 54,2\%) em relação aos tratamentos BM (40,32\%) e LF+BM (33,89\%). Já nos blastocistos obtidos em D8 e vitrificados, observou-se menor taxa de eclosão do grupo controle (TCM) quando comparados com os blastocistos D7 (Tabela 2). Já para os tratamentos BM, LF e LF+BM não houve diferença nas taxas de eclosão entre os blastocistos D7 e D8. Esses dados reforçam o possível efeito positivo do BM no meio de maturação quando as estruturas são de baixa qualidade e mais sujeitas ao estresse oxidativo. Devido a isso, esses embriões têm menor potencial de desenvolvimento, como é o caso dos blastocistos mais tardios obtidos em D8. Como demonstrado na Tabela 3, o número de células embrionárias foi semelhante em todos os tratamentos, evidenciando que os embriões, embora em menor quantidade, apresentam viabilidade in vitro similar.

Os embriões produzidos a partir de oócitos vitrificados, neste estudo, apresentaram desenvolvimento mais lento, com 83 a 100\% das eclosões ocorrendo após o dia 9 de cultivo, diferente do comportamento dos embriões não vitrificados, em que apenas 38,2\% das eclosões foram verificadas após D9. Esse comportamento deve ser considerado, tanto na avaliação in vitro quanto na avaliação in vivo, após transferência. Os parâmetros de viabilidade obtidos nos dois experimentos são semelhantes aos observados em estudos prévios e na rotina de PIV de embriões conduzidos em nosso 
laboratório. A limitação prática para o uso de LF poderá ser contornada pela identificação e adição de substâncias presentes no LF que naturalmente participem do bloqueio meiótico ou promovam a maturação citoplasmática.

Tabela 3: Número médio de células e erro padrão de blastocistos eclodidos após vitrificação (Experimento 2), em função do grau de qualidade (G1, G2 ou G3) e dos diferentes tratamentos de maturação

\begin{tabular}{lcccc}
\hline Tratamento & Grau 1 & Grau 2 & Grau 3 & Total \\
\hline TCM & $123,9 \pm 15,4[6]$ & $111,3 \pm 16,9[5]$ & $102,4 \pm 15,4[6]$ & $112,5 \pm 9,2[17]$ \\
BM & $152,29 \pm 14,3[7]$ & $133,1 \pm 14,3[7]$ & $94,9 \pm 15,4[6]$ & $126,8 \pm 8,5[20]$ \\
LF & $169,81 \pm 13,4[8]$ & $119,7 \pm 15,4[6]$ & $91,1 \pm 19,0[4]$ & $126,9 \pm 9,3[18]$ \\
LF+BM & $171,93 \pm 14,3[7]$ & $120,5 \pm 18,9[4]$ & $112,0 \pm 26,7[3]$ & $134,8 \pm 12[13]$ \\
\hline
\end{tabular}

[n] = número de estruturas coradas.

\section{Conclusões}

A exposição ao LF por um período de $6 \mathrm{~h}$ na pré-maturação, com ou sem a adição de BM no meio de maturação, não melhora as taxas de desenvolvimento nem a qualidade de embriões produzidos a partir de oócitos imaturos vitrificados. De forma semelhante, esses tratamentos não melhoram o desenvolvimento e a criotolerância de embriões PIV, produzidos a partir de oócitos frescos.

A vitrificação de oócitos determina um retardo na eclosão dos embriões, com número significativo de estruturas eclodindo tardiamente, em contraste com oócitos não vitrificados.

Com base nas taxas de eclosão, blastocistos mais precoces (D7) tem maior criotolerância em relação aos mais tardios (D8).

$\mathrm{A}$ adição de $\mathrm{BM}$ ou $\mathrm{LF}+\mathrm{BM}$ apresenta efeitos distintos com blastocistos $\mathrm{D} 7$ vitrificados, em que induz a redução da eclosão, porém não interfere na eclosão de blastocistos D8 vitrificados.

\section{Referências}

1. Vieria AD, Mezzalira A, Barbieri DP, Lehmkuhl RC, Rubin MIB, Vajta G. Calves born after open pulled straw vitrification of immature bovine oocytes. Cryobiology. 2002;45(1):91-94.

2. Santos RM, Barreta MH, Frajblat M, Cucco DC, Mezzalira JC, Bunn S, Cruz FB, Vieira AD, Mezzalira A. Vacuum-cooled liquid nitrogen increases the developmental ability of vitrified-warmed bovine oocytes. Ciência Rural. 2006;36(5):1501-1506.

3. Werlich DE, Barreta MH, Martins LT, Vieira AD, Moraes AN, Mezzalira A. Embriões bovinos PIV vitrificados em diferentes soluções crioprotetoras com ou sem o uso de nitrogênio super-resfriado. Acta Scientiae Veterinariae. 2006;34(1):77-82.

4. Bunn S, Cruz FB, Pedrazzi CAF, Bertolini M, Vieira AD, Mezzalira A. Aumento na sobrevivência após vitrificação de oócitos bovinos imaturos em recipientes com maior condutividade térmica e nitrogênio superresfriado. Acta Scientiae Veterinarie. 2008;36(3):255-261. 
5. Vajta G, Kuwayama M. Improving cryopreservation systems. Theriogenology. 2006;65(1):236-244.

6. Räty M, Ketoja E, Pitkänen T, Ahola V, Kananen K, Peippo J. In vitro maturation supplements affect developmental competence of bovine cumulus-oocyte complexes and embryo quality after vitrification. Cryobiology. 2011;63(3):245-55.

7. Duranthon V, Renard J. The developmental competence of mammalian oocytes: a convenient but biologically fuzzy concept. Theriogenology. 2001;55(6):1277-1289.

8. Sirard MA, Richard F, Mayes MA. Controlling meiotic resumption in bovine oocytes: a review. Theriogenology. 1998;49(2):483-497.

9. Alves DF, Silva CAM, Rubin MIB, Rauber LP, Pessoa GA, Mozzaquatro FD, Bernardi ML. Does the follicular fluid obtained from bovine follicles of differente diameter influence oocytes development? Veterinária e Zootecnia (UNESP). 2011;18(1):22-30.

10. Coleman NV, Shagiakhmetova GA, Lebedeva IY, Kuzmina TI, Golubev AK. In vitro maturation and early developmental capacity of bovine oocytes cultured in pure follicular fluid and supplementation with follicular wall. Theriogenology. 2007;67(5):1053-1059.

11. Iwata H, Hashimoto S, Ohota M, Kimura K, Shibano K, Miyake M. Effects of follicle size and electrolytes and glucose in maturation médium on nuclear maturation and developmental competence of bovine oocytes. Reproduction. 2004;127(2):159-164.

12. Agarwal A, Said TM, Bedaiwy MA, Banerjee J, Alvarez JG. Oxidative stress in an assisted reproductive techniques setting. Fertility and Sterility. 2006;86(3):503-512.

13. Esfandiari N, Falcone T, Goldberg JM, Agarwal A, Sharma RK. Heat-shock proteins modulate the incidence of apoptosis and oxidative stress in pre-implantation mouse embryos. Fertility and Sterility. 2007;87(5):1214-1217.

14. Ott M, Gogvadze V, Orrenius S, Zhivotovsky B. Mitochondria, oxidative stress and cell death. Apoptosis. 2007;12(5):913-922.

15. Deleuze S, Goudet G. Cysteamine Supplementation of In vitro Maturation Media: A Review. Reproduction in Domestic Animals. 2010;45(6):476-482.

16. Combelles CMH, Holick EA, Paolella LJ, Walker DC, Wu Q. Profiling of superoxide dismutase isoenzymes in compartments of the developing bovine antral follicles. Reproduction. 2010;139(5):871-881.

17. Arias ME, Sanchez R, Felmer R. Evaluation of different culture systems with low oxygen tension on the development, quality and oxidative stress-related genes of bovine embryos produced in vitro. Zygote. 2012;20(3):209-217.

18. Lonergan P, Fair T, Corcoran D, Evans ACO. Effect of culture environment on gene expression and developmental haracteristics in IVF-derived embryos. Theriogenology. 2006;65(1):137-152.

19. De Matos DG, Furnus CC. The importance of having glutatione (GSH) level after bovine in vitro maturation on embryo development: effect of $\beta$-mercaptoetanol, cysteine and cystine. Theriogenology. 2000;53(3):761-771.

20. Knappen MFCM, Zusterzeel PLM, Peters WHM, Steegers EAP. Glutathione and glutathione-related enzymes in reproduction: a review. European Journal of Obstetrics and Gynecology and Reproductive Biology. 1999;82(2):171-184.

21. Furnus CC, De Matos DG, Picco S, García PP, Inda AM, Mattioli G, Errecalde AL. Metabolic requirements associated with GSH synthesis during in vitro maturation of cattle oocytes. Animal Reproduction Science. 2008;109(1-4):88-99. 
22. Caamaño JN, Ryoo ZY, Thomas JA, Youngs CR. $\beta$-Mercaptoethanol enhances blastocyst formation rate of bovine in vitro-matured/in vitro-fertilized embryos. Biology of Reproduction. 1996;55(5):1179-1184.

23. Choe C, Shin YW, Kim EJ, Cho SR, Kim HJ, Choi SH, Han MH, Han J, Son DS, Kang D. Synergistic effects of glutathione and $\beta$-mercaptoethanol treatment during in vitro maturation of porcine oocytes on early embryonic development in a culture system supplemented with L-cysteine. Journal of Reproduction and Development. 2010;56(6):575-82.

24. Lehmkuhl RC, Mezzalira A, Vieira AD, Barbieri DP, Machado MF, Rubin MIB, Silva CAM. Viabilidade de oócitos bovinos mantidos em líquido folicular. ARS Veterinária. 2002;18(3):273-279.

25. Vajta G, Holm P, Greve T, Callesen H. The submarine incubation system, a new tool for in vitro embryo culture: a technique report. Theriogenology. 1997;48(8):1379-1385.

26. Ayoub MA, Hunter AG. Inhibitory effect of bovine follicular fluid on in vitro maturation of bovine oocytes. Journal of Dairy Science. 1993;76(1):95-100.

27. Sutton ML, Gilchrist RB, Thompson JG. Effects of in vivo and in vitro environments on the metabolism of the cumulus-oocyte complex and its influence on oocyte developmental capacity. Human Reproduction Update. 2003;9(1):35-48.

28. Carbone MC, Tatone C, Delle Monache S, Marci R, Caserta D, Colonna R, Amicarelli F. Antioxidant enzymatic defenses in human follicular fluid: characterization and age-dependent changes. Molecular Human Reproduction. 2003;9(11):639-643.

29. Gupta S, Choi A, Yu HY, Czerniak SM, Holick EA, Paolella LJ, Agarwal A, Combelles CMH. Fluctuations in total antioxidant capacity, catalase activity, and hydrogen peroxide levels of follicular fluid during bovine folliculogenesis. Reproduction, Fertility and Development. 2011;23(5):673-680.

30. Bai J, Hou J, Guan H, Yan F, Cui X, Liu L, Wang S, An X. Effect of $\beta$-mercaptoethanol and cysteine supplementation during in vitro maturation on the developmental competence of oocytes from hormonestimulated lambs. Theriogenology. 2008;70(5):758-764.

31. Hosseini SM, Forouzanfar M, Hajian M, Asgari V, Abedi P, Hosseini L, Ostadhosseini S, Moulavi F, Safahani Langrroodi M, Sadeghi H, Bahramian H, Eghbalsaied SH, Nasr-Esfahani MS. Antioxidant supplementation of culture medium during embryo development and/or after vitrification-warming; which is the most important? Journal of Assisted Reproduction and Genetics. 2009;26(6):355-364.

32. Agarwal A, Gupta S, Sharma RK. Role of oxidative stress in female reproduction. Reproductive Biology and Endocrinology. 2005;3:28. Available from: http://www.rbej.com/content/3/1/28

33. Balasubramanian S, Rho G. Effect of cysteamine supplementation of in vitro matured bovine oocytes on chilling sensitivity and development of embryos. Animal Reproduction Science. 2007;98(3-4):282-292.

34. Nedambale TL, Du F, Yang X, Tian XC. Higher survival rate of vitrified and thawed in vitro produced bovine blastocysts following culture in defined medium supplemented with $\beta$-mercaptoethanol. Animal Reproduction Science. 2006;93(1-2):61-75.

35. Gupta MK, Uhm SJ, Lee HT. Effect of vitrification and beta-mercaptoethanol on reactive oxygen species activity and in vitro development of oocytes vitrified before or after in vitro fertilization. Fertility and Sterility. 2010;93(8):2602-2607. 